\title{
Conceptual Design of Divertor Cassette Handling by Remote Handling System of JT-60SA*
}

\author{
Takao HAYASHI**, Shinji SAKURAI**, Kei MASAKI**, Hiroshi TAMAI**, \\ Kiyoshi YOSHIDA** and Makoto MATSUKAWA** \\ ** Japan Atomic Energy Agency \\ 801-1, Mukouyama, Naka, Ibaraki 311-0193, Japan \\ E-mail: hayashi.takao@jaea.go.jp
}

\begin{abstract}
The JT-60SA aims to contribute and supplement ITER toward demonstration fusion reactor based on tokamak concept. One of the features of JT-60SA is its high power long pulse heating, causing the large annual neutron fluence. Because the expected dose rate at the vacuum vessel (VV) may exceed $1 \mathrm{mSv} / \mathrm{hr}$ after 10 years operation and three month cooling, the human access inside the VV is restricted. Therefore a remote handling $(\mathrm{RH})$ system is necessary for the maintenance and repair of in-vessel components. This paper described the RH system of JT-60SA, especially the expansion of the RH rail and exchange of the divertor cassettes. The RH rail is divided into nine and three-point mounting. The nine sections can cover 225 degrees in toroidal direction. A divertor cassette, which is 10 degrees wide in toroidal direction and weighs $500 \mathrm{~kg}$ itself due to the limitations of port width and handling weight, can be exchanged by heavy weight manipulator (HWM). The HWM brings the divertor cassette to the front of the other RH port, which is used for supporting the rail and/or carrying in and out equipments. Then another RH device receives and brings out the cassette by a pallet installed from outside the VV.
\end{abstract}

Key words: Remote Handling, JT-60SA, Divertor Cassette, In-Vessel Components, Heavy Weight Manipulator, RH Rail

\section{Introduction}

JT-60SA ${ }^{(1)(2)}$ aims to contribute and supplement ITER toward demonstration (DEMO) fusion reactor based on tokamak concept. The JT-60SA equipped with fully superconducting magnets is now being designed as a combined project of the Japanese national project toward DEMO reactor and a satellite tokamak project for ITER in a broader approach with Japan and EU collaboration. One of the features of JT-60SA is its high power (more than $41 \mathrm{MW}$ ) long pulse (100 s) heating, causing the large annual neutron fluence of $4 \times 10^{21}$ neutrons/year. The vacuum vessel is made by low cobalt $(0.05$ $\mathrm{wt} \%$ ) stainless steel, SUS316L, in order to reduce radio activation. However, because the expected dose rate at the vacuum vessel (VV) may exceed $1 \mathrm{mSv} / \mathrm{hr}$ after 10 years operation and three month cooling, the human access inside the VV is restricted. This indicates a remote handling $(\mathrm{RH})$ system is necessary for the maintenance and repair of in-vessel components. 


\section{Design Requirements and General Concept}

The major and minor radii of JT-60SA are 3.06 and $1.15 \mathrm{~m}$, respectively. Figure 1 shows the poloidal cross section of the vacuum vessel and in-vessel components. The remote-handled objectives are shown in Table $1^{(3)}$. Divertor, first wall, NB duct armor for re-ionization loss, cryopanel, sensors and diagnostics are exchanged and/or repaired by the RH system. Because almost all remote-handled objectives are bolted and water-cooled, the functions of cutting and re-welding of cooling pipes are necessary for exchange.

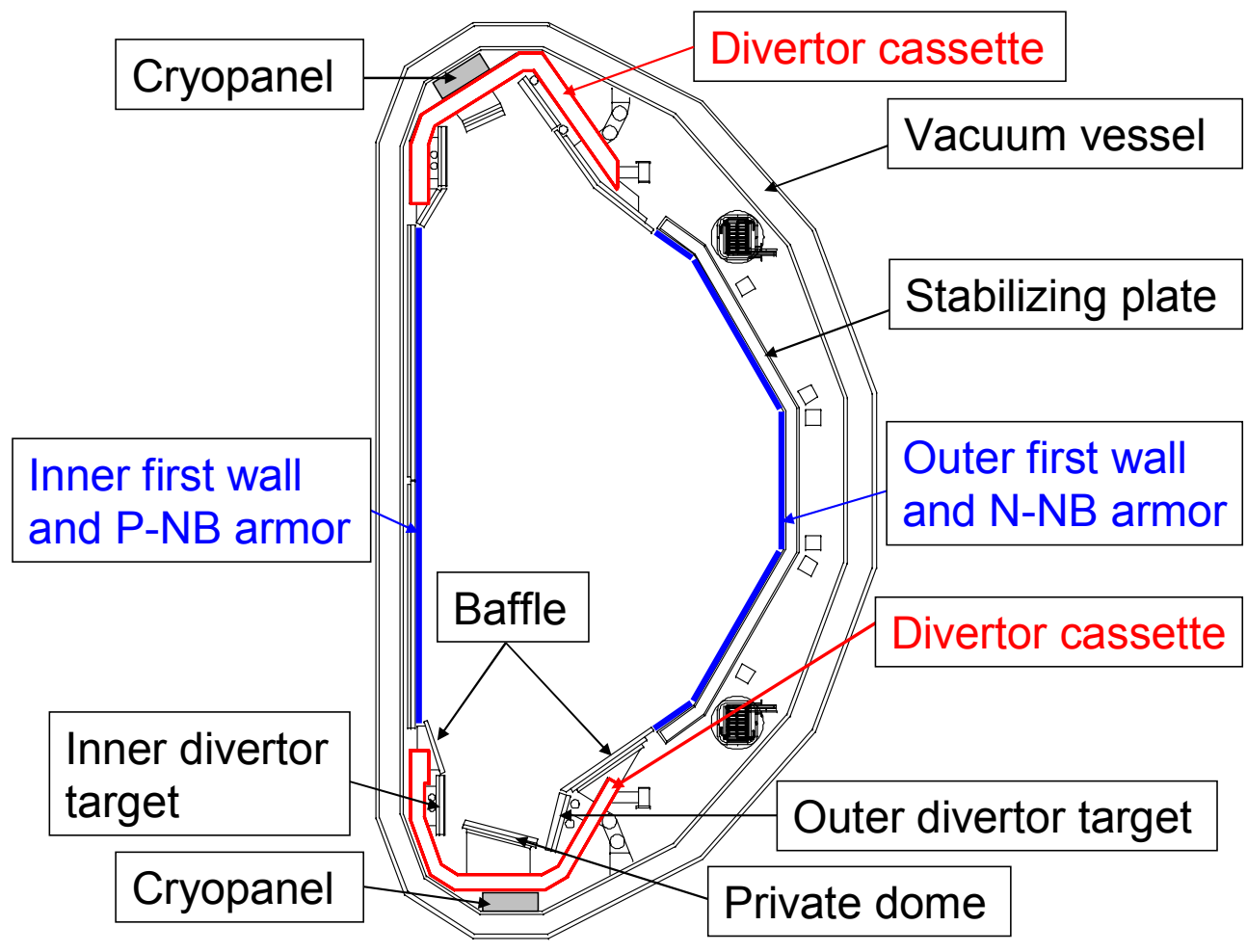

Fig. 1 Poloidal cross section of the vacuum vessel and in-vessel components of JT-60SA. Divertor, first wall and cryopanel are exchanged and/or repaired by the RH system.

Table 1 List of remote-handled objectives.

\begin{tabular}{|c|c|c|c|c|}
\hline \multicolumn{3}{|c|}{ Components } & Purpose & Maintained at \\
\hline \multirow{7}{*}{ Divertor } & \multirow{2}{*}{$\begin{array}{l}\text { Inner and } \\
\text { outer targets }\end{array}$} & Target plates & Repair, Modification & Outside of VV \\
\hline & & Support & Repair, Modification & Outside of VV \\
\hline & \multirow{2}{*}{ Private dome } & Armor tiles & Material test, Repair, Modification & Inside of VV \\
\hline & & Heatsink, support & Repair, Modification & Outside of VV \\
\hline & \multirow{2}{*}{$\begin{array}{l}\text { Inner and } \\
\text { outer baffle }\end{array}$} & Armor tiles & Material test, Repair, Modification & Inside of VV \\
\hline & & Heatsink, support & Repair, Modification & Outside of VV \\
\hline & \multicolumn{2}{|l|}{ Cassette } & Repair, Modification & Outside of VV \\
\hline \multirow{5}{*}{ First wall } & \multicolumn{2}{|c|}{ Inboard armor tiles, P-NB armor tiles } & Material test, Repair & Inside of VV \\
\hline & \multicolumn{2}{|c|}{ Inboard heatsink } & \multicolumn{2}{|l|}{ Repair or permanent } \\
\hline & \multicolumn{2}{|c|}{$\begin{array}{l}\text { Outboard armor tiles, T-NB armor } \\
\text { tiles }\end{array}$} & Material test, Repair & Inside of $\mathrm{VV}$ \\
\hline & \multicolumn{2}{|c|}{ N-NB armor target } & Repair & Outside of VV \\
\hline & \multicolumn{2}{|c|}{ Stabilizing plate } & \multicolumn{2}{|l|}{ Permanent, only inspection } \\
\hline \multicolumn{3}{|c|}{ NB duct armor for re-ionization loss } & \multicolumn{2}{|l|}{ Repair or permanent } \\
\hline \multicolumn{3}{|c|}{ Header and pipes for coolant } & \multicolumn{2}{|l|}{ Permanent, only inspection } \\
\hline \multirow{2}{*}{ Cryopanel } & \multicolumn{2}{|l|}{ Cryopanel } & Repair, Modification & Outside of VV \\
\hline & \multicolumn{2}{|l|}{ Coolant pipes } & \multicolumn{2}{|l|}{ Permanent, only inspection } \\
\hline \multicolumn{3}{|c|}{ Sensors, Diagnostics } & Calibration, Repair, Modification & Inside of VV \\
\hline
\end{tabular}




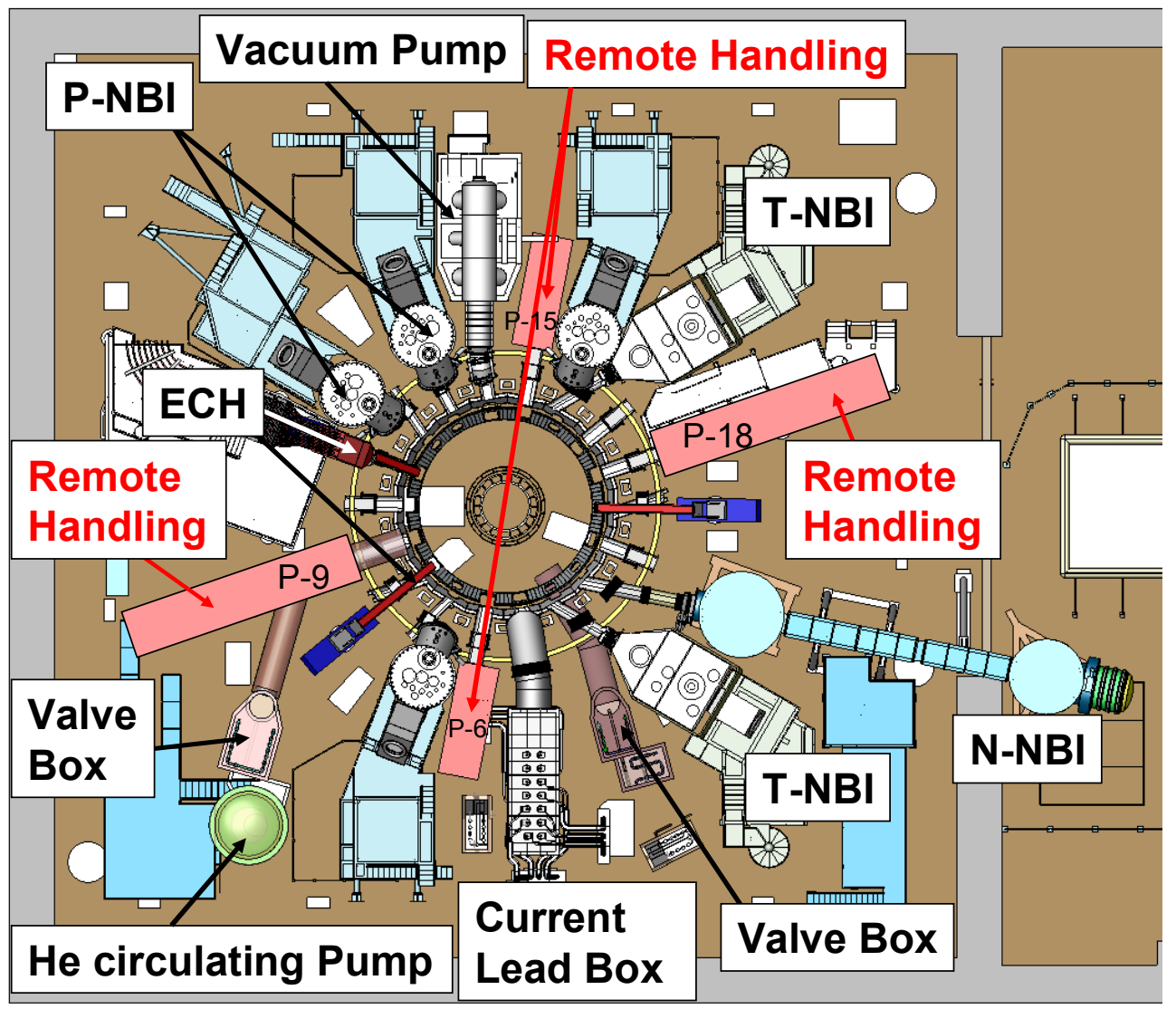

Fig. 2 Allocation in torus hall of JT-60SA. Four large horizontal ports are used for RH system.

Figure 2 shows an allocation of RH containers in torus hall. Four large horizontal ports $(0.6 \mathrm{~m}$ wide and $1.9 \mathrm{~m}$ high $)$ are used to extend and support a rail and bring in/out maintained components. The RH components are carried by two kinds of containers to the torus hall as shown in Fig. 2. The sizes of the large and small containers are $10 \times 2 \times 2^{\mathrm{H}}$ $\mathrm{m}$ and $5 \times 2 \times 2^{\mathrm{H}} \mathrm{m}$, respectively. During the operation period, $4 \times 10^{21}$ neutrons are produced per year by D-D reactions. Consequently, $4 \times 10^{21}$ or $7 \mathrm{TBq}$ of tritium was also produced per year. The in-vessel components contaminated by tritium are brought to the RH containers. Because the containers are also tritium boundary, the in-vessel components brought out by RH system are decontaminated in the RH containers. The RH system of JT-60SA is a vehicle type system adopted in ITER with a possibility to use its rail as a boom. The RH system equips a heavy weight manipulator (HWM) and a light weight manipulator (LWM).

\section{Rail as a Boom}

Expansion and support of the RH rail are shown in Fig. 3. The RH rail is divided into nine. The long rail is three-point mounting. The connection of the RH rail is shown in Fig. 4. 


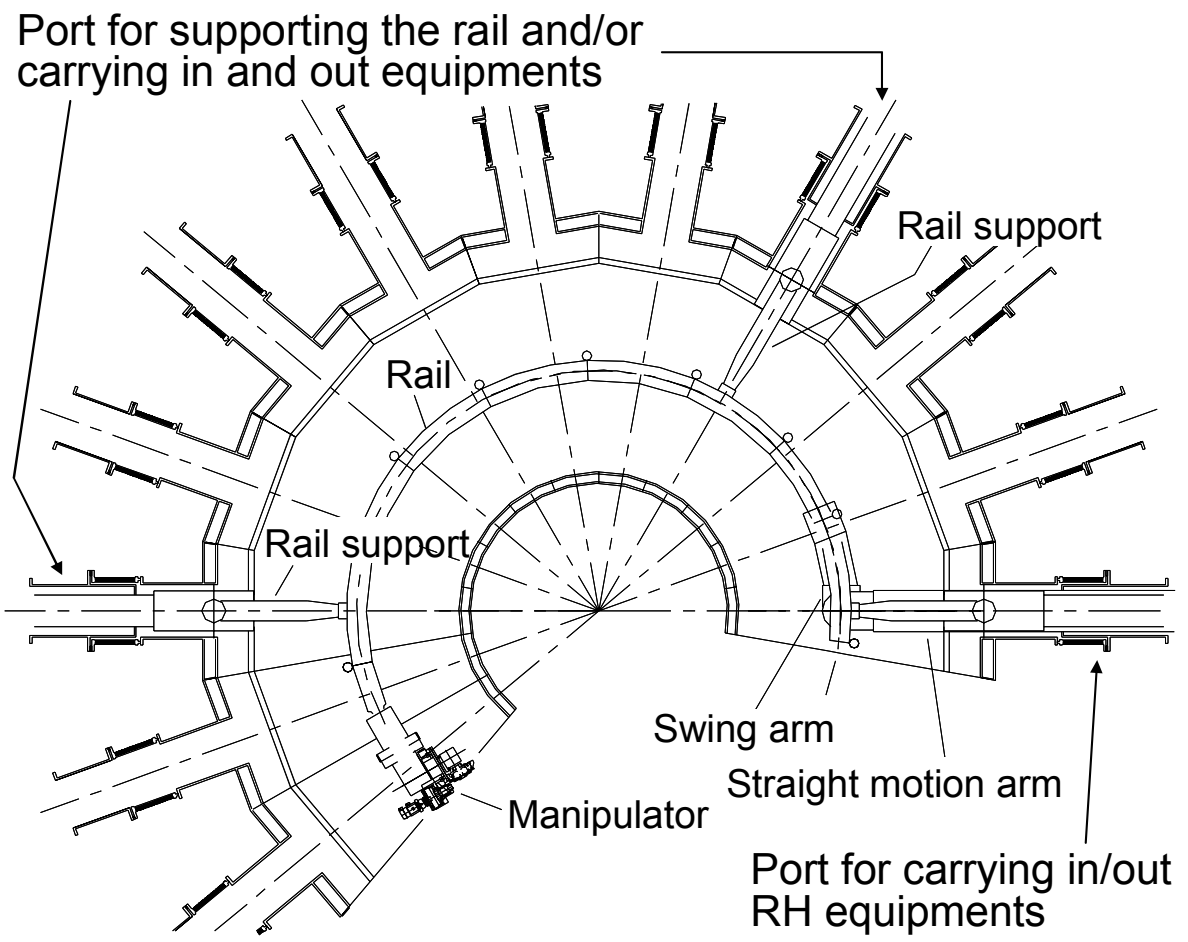

Fig. 3 Expansion and support of the RH rail. The RH rail is divided into nine and three-point mounting.

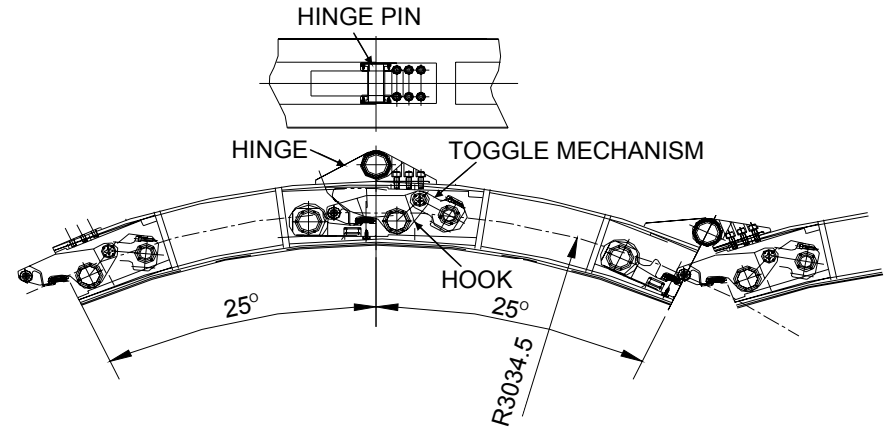

Fig. 4 Connection of the RH rail. The toroidal angle of a section is 25 degrees.

The toroidal angle and the length of a section are 25 degrees and $1.3 \mathrm{~m}$, respectively. The nine sections can cover 225 degrees in toroidal direction. The rail employs the hinge and toggle mechanisms. Figure 5 shows the head of the RH rail. The HWM is assembled at the distal end of the RH rail as a boom. The RH rail is expanded one step at a time. The procedures for expanding the RH rail are shown in Fig. 6(a)-(d). When first wall armors are exchanged, the vehicle of LWM can move toroidally on the rail. 


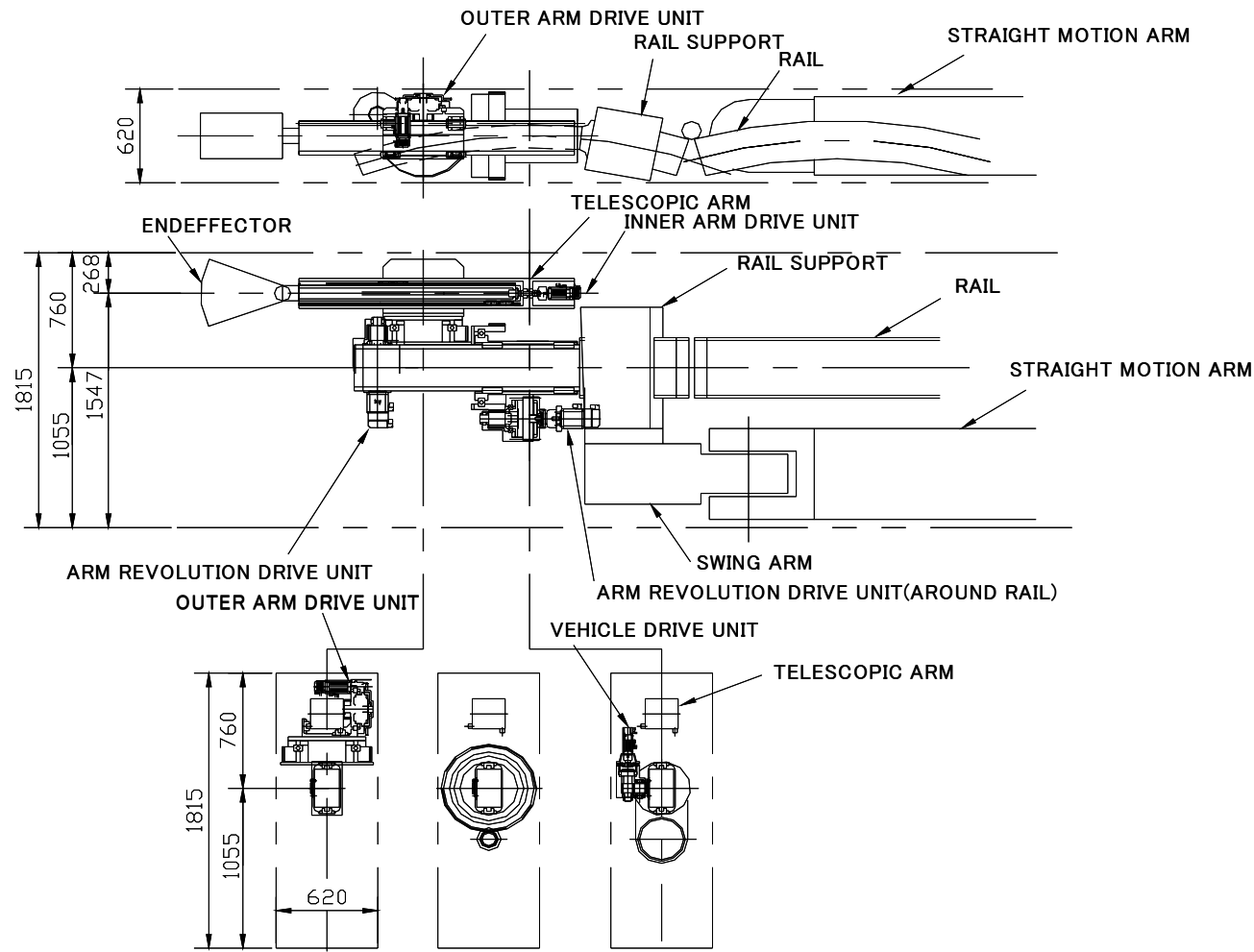

Fig. 5 Head of the RH rail. The HWM is assembled at the distal end of the RH rail as a boom.
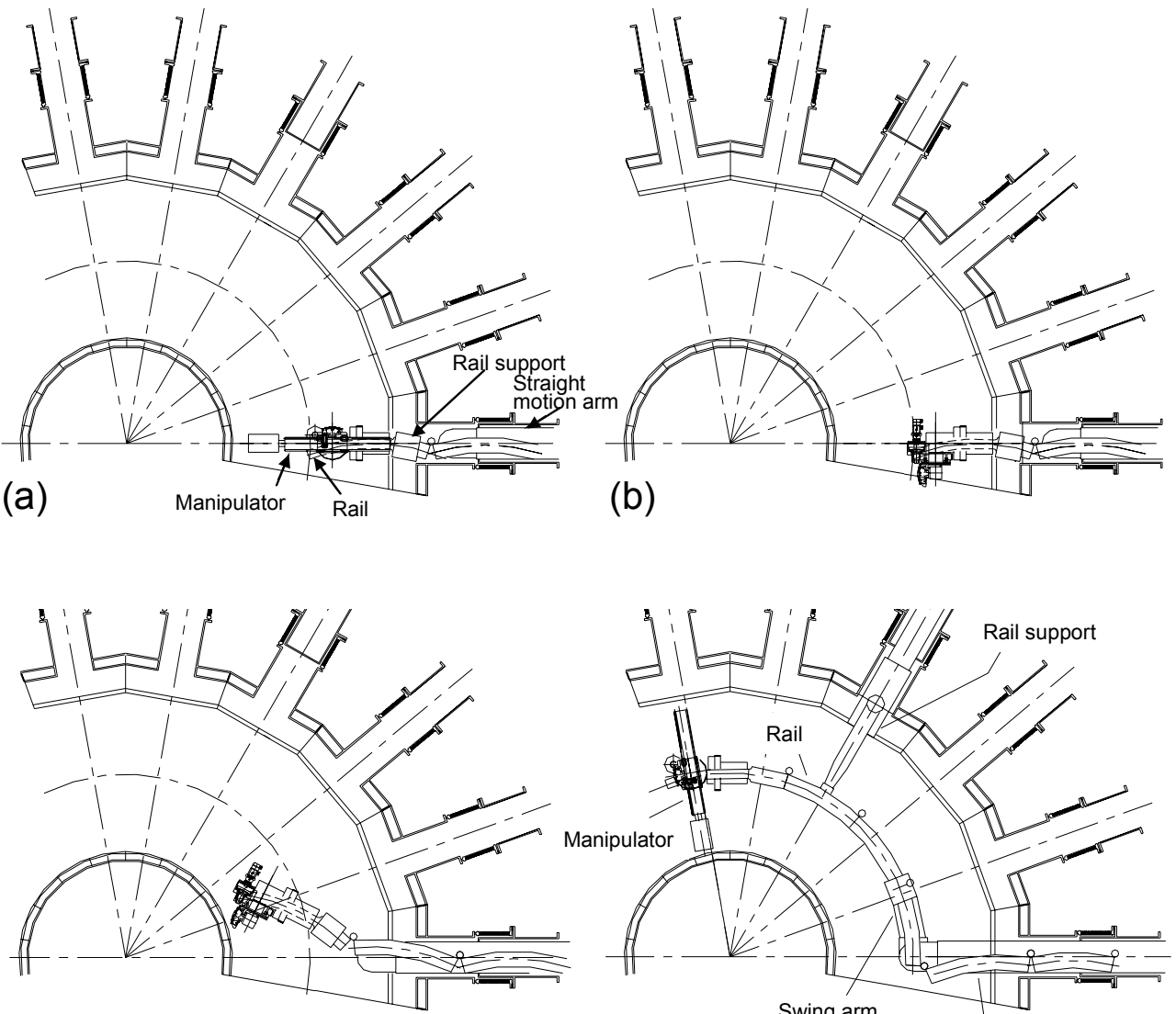

(c)

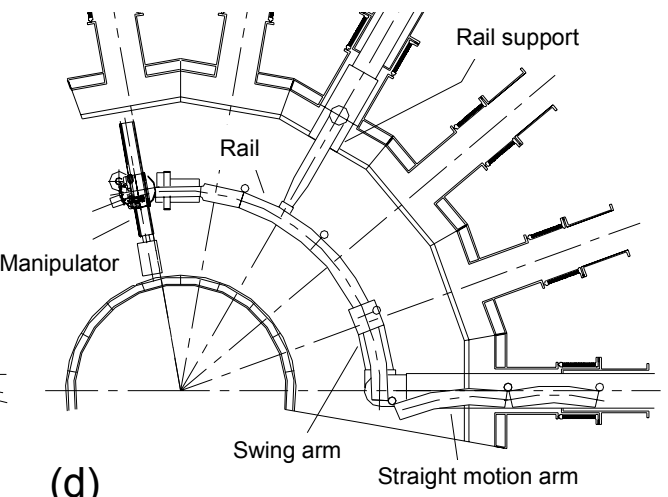

Fig. 6 Procedures for expanding the RH rail. The RH rail is expanded one step at a time. 


\section{Divertor Cassette Handling}

A divertor cassette, which is 10 degrees wide in toroidal direction and weighs $500 \mathrm{~kg}$ itself due to the limitations of port width and handling weight, can be exchanged by HWM. Because the divertor targets are water-cooled, the cooling pipes of the divertor cassette are cut and re-welded by laser before and after exchange of the cassette, respectively.

Figure 7 (a) shows the configuration for holding the lower divertor cassette by the HWM with an end-effecter frame. Some armor tiles of divertor cassettes are removed in order to cut the cooling pipes, to dismount and grip the divertor cassette. The HWM equips a double-banked telescopic arm, which can be rotated in the toroidal and poloidal cross sections as shown in Fig. 7 (b).

Figure 8 (a)-(d) show the procedures for removing the lower divertor cassette. The HWM lifts and brings the divertor cassette to the front of the other RH port, which is used for supporting the rail and/or carrying in and out equipments. Then another RH device receives and brings out the cassette by a pallet installed from outside the VV. The divertor cassette removed from VV is carried by an exclusive container from torus hall. Then divertor components on the cassette can be exchanged and maintained at outside the VV.
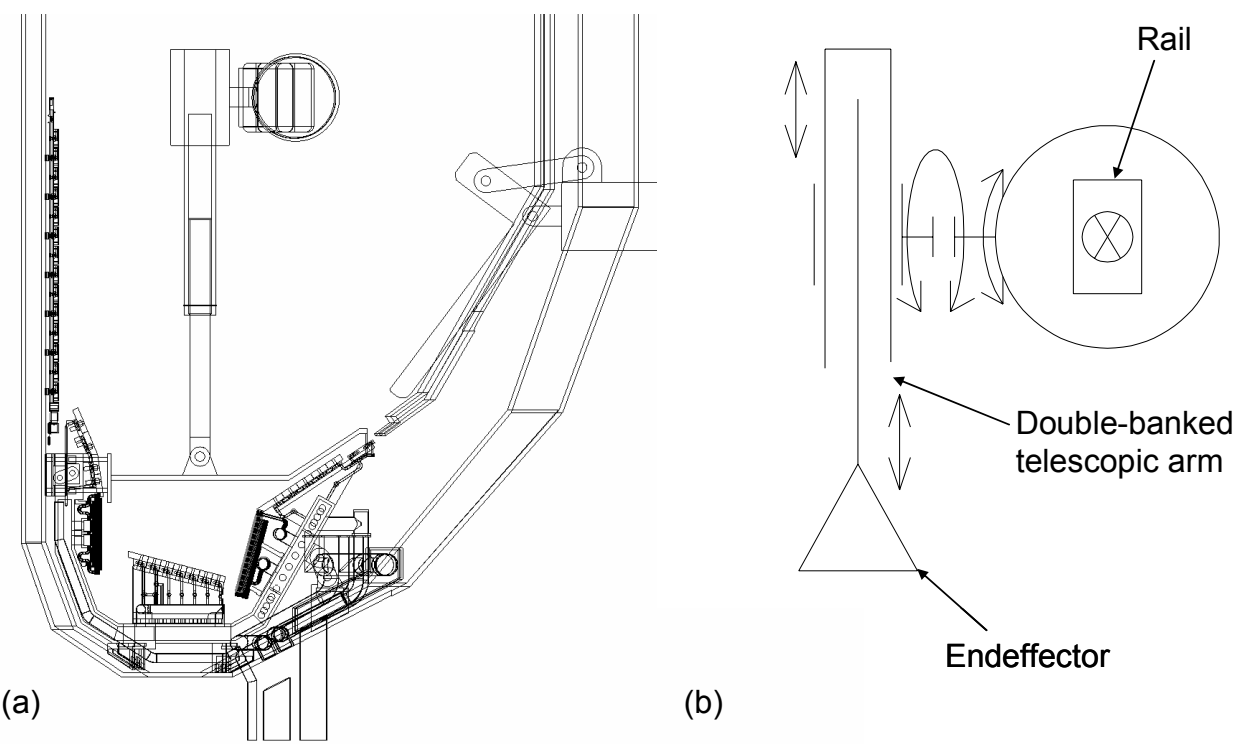

(b)

Fig. 7 Configuration for holding the lower divertor cassette by the HWM with double-banked telescopic arm. 


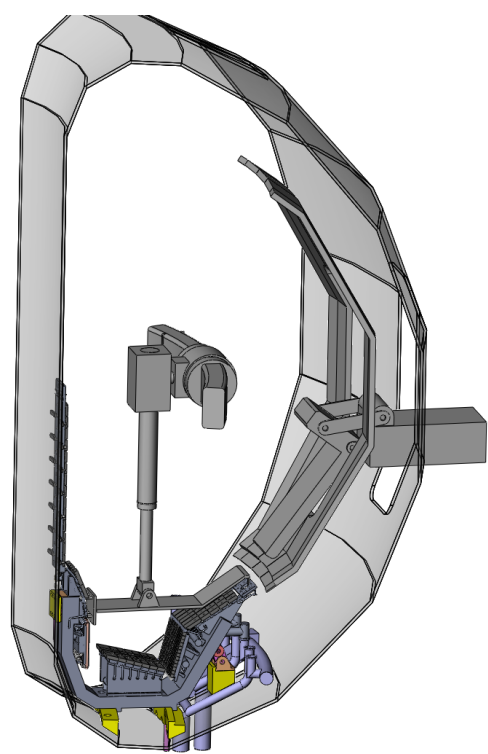

(a)

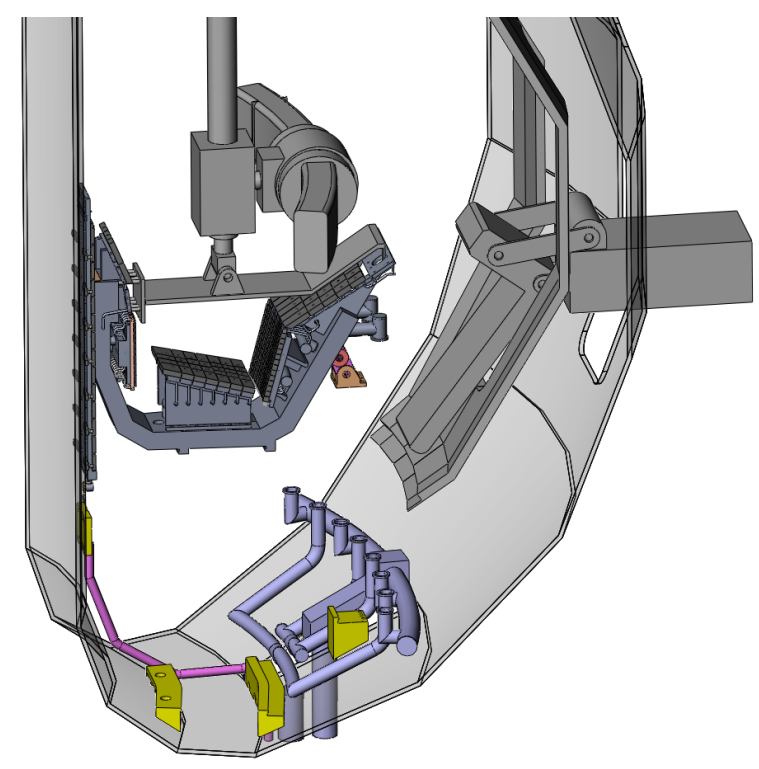

(b)

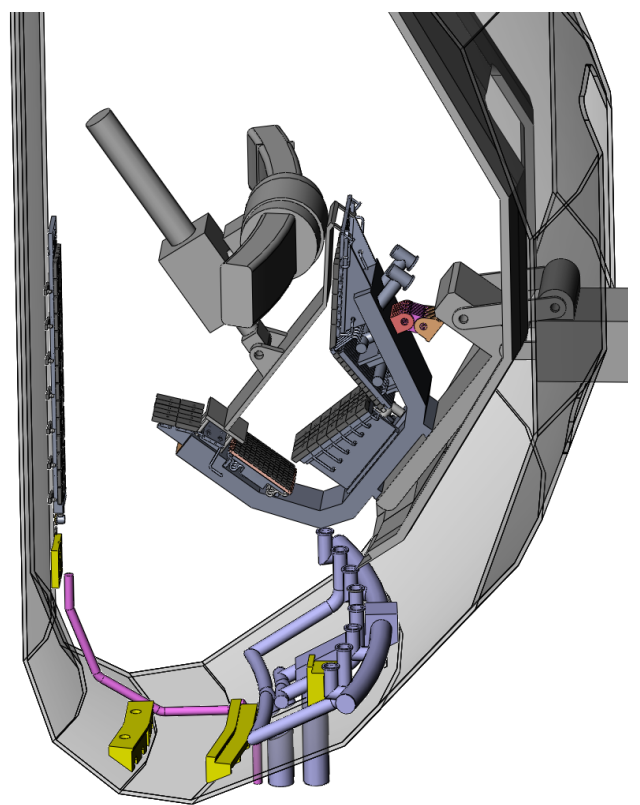

(c)

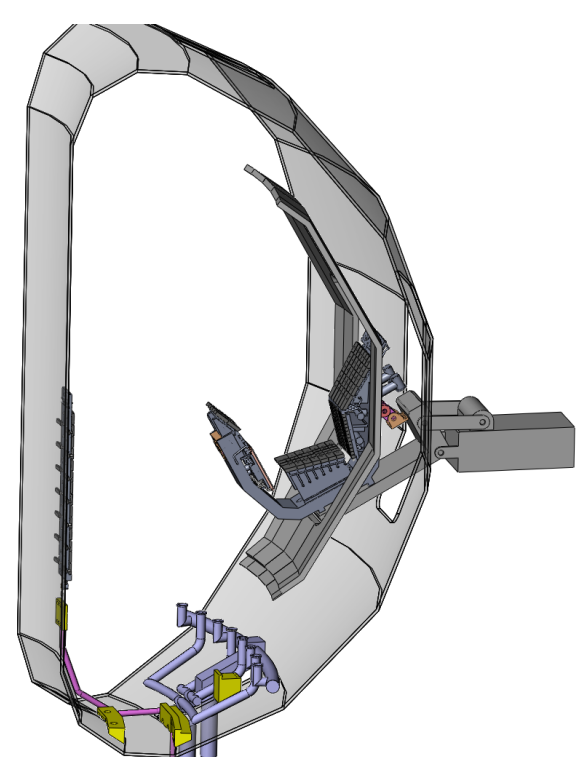

(d)

Fig. 8 Procedures for removing the lower divertor cassette. The divertor cassette is brought out by a pallet

\section{Conclusions}

Conceptual design of divertor cassette handling by remote handling system for JT-60SA has been carried out. The RH system of JT-60SA is a vehicle type system adopted in ITER with a possibility to use its rail as a boom.

The RH rail is divided into nine and three-point mounting. The nine sections can cover 225 degrees in toroidal direction. A divertor cassette, which is 10 degrees wide in toroidal direction and weighs $500 \mathrm{~kg}$ itself due to the limitations of port width and handling weight, can be exchanged by HWM. The HWM lifts and brings the divertor 
cassette to the front of the other RH port, which is used for supporting the rail and/or carrying in and out equipments. Then another RH device receives and brings out the cassette by a pallet installed from outside the VV. Then the cassette is maintained at outside the VV.

\section{References}

(1) Kikuchi, M., et al., Overview of Modification of JT-60U for the Satellite Tokamak Program as one of the Broader Approach Projects and National Program, Proceedings of the 21st IAEA Fusion Energy Conference, Chengdu (2006-10).

(2) Matsukawa, M., et al., Engineering Feature in the Design of JT-60SA, Proceedings of the 21st IAEA Fusion Energy Conference, Chengdu (2006-10).

(3) Sakurai, S., Masaki, K., Shibama, Y. K., Tamai, H. and Matsukawa, M., Design Study of Plasma Facing Components for JT-60SA, Fusion engineering and design 82 (2007) $1767-1773$. 